\title{
Supplemental Materials \\ Episodic Impacts from California Wildfires Identified in Las Vegas Urban Air Quality Monitoring
}

Sue Kimbrough ${ }^{\dagger^{*}}$, Michael Hays ${ }^{\dagger}$, Bill Preston ${ }^{\S}$, Daniel A. Vallero ${ }^{\ddagger}$, Gayle S.W. Hagler ${ }^{\dagger}$,

${ }^{\dagger}$ U.S. Environmental Protection Agency, Office of Research and Development, National Risk

Management Research Laboratory, Durham, NC 27709.

${ }^{\S}$ ARCADIS-US, Inc., 4915 Prospectus Drive, Suite F, Durham, North Carolina 27713 (now with CSS-

Dynamac, 1910 Sedwick Road, Durham, NC 27713)

${ }^{\ddagger}$ U.S. Environmental Protection Agency, Office of Research and Development, National

Exposure Research Laboratory, Durham, NC 27709.

*Corresponding Author: 109 T.W. Alexander Drive, Durham, NC 27709. Phone: (919) 541-

2612. E-mail: kimbrough.sue@epa.gov

Number of pages $=14$

Number of figures $=7$ 


\section{Supplemental Materials}

\section{Episodic Impacts from California Wildfires Identified in Las Vegas Urban Air Quality Monitoring}

Sue Kimbrough ${ }^{\dagger^{*}}$, Michael Hays ${ }^{\dagger}$, Bill Preston ${ }^{\S}$, Daniel A. Vallero ${ }^{\dagger}$, Gayle S.W. Hagler ${ }^{\dagger}$, ${ }^{\dagger}$ U.S. Environmental Protection Agency, Office of Research and Development, National Risk Management Research Laboratory, Durham, NC 27709.

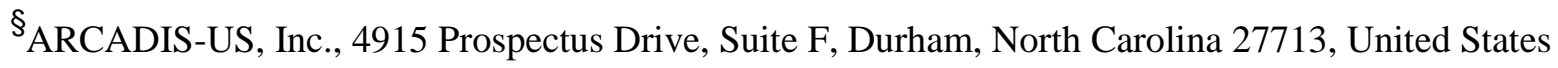
(now with CSS-Dynamac, 1910 Sedwick Road, Durham, NC 27713, United States)

${ }^{\ddagger}$ U.S. Environmental Protection Agency, Office of Research and Development, National Exposure Research Laboratory, Durham, NC 27709.

*Corresponding Author: 109 T.W. Alexander Drive, Durham, NC 27709. Phone: (919) 541-2612. E-mail: kimbrough.sue@epa.gov

La Brea Wildfire and Station Wildfire. Of the dozens of wildfires that burned across the State of California during 2009, two were especially notable due to the size of the fires, loss of life and property. The La Brea fire (August 8 - August 22, 2009) began as the result of a propane stove being operated at the site of an illegal marijuana plantation. ${ }^{1}$ The Station fire began on August 26, 2009 in the Angeles National Forest. This fire, burning for several weeks, consumed more than 160,000 acres. The fire was fully contained on October 16, 2009. It was the largest wildfire ever recorded for the Angeles National Forest and the $10^{\text {th }}$ largest fire in California since $1933 .^{2}$

These episodic wildfire events in California impacted Las Vegas ambient air quality. As a result of these fires and transport of air pollutants into the Las Vegas urban area, an air quality 
advisory was issued by Clark County Department of Air Quality and Environmental Management (DAQEM) for smoke from wildfires burning in Southern California from August 13 thru August 16, 2009 (La Brea fire). ${ }^{3}$ Air quality advisories were issued by Clark County Department of Air Quality and Environmental Management (DAQEM) for ground-level ozone due to smoke from wildfires burning in Southern California from August 29 thru September 2, 2009 (Station fire). $^{3}$

Las Vegas Project Sites. Figure S1 shows a map of the Las Vegas monitoring sites and the location of the city relative to the rest of the United States.

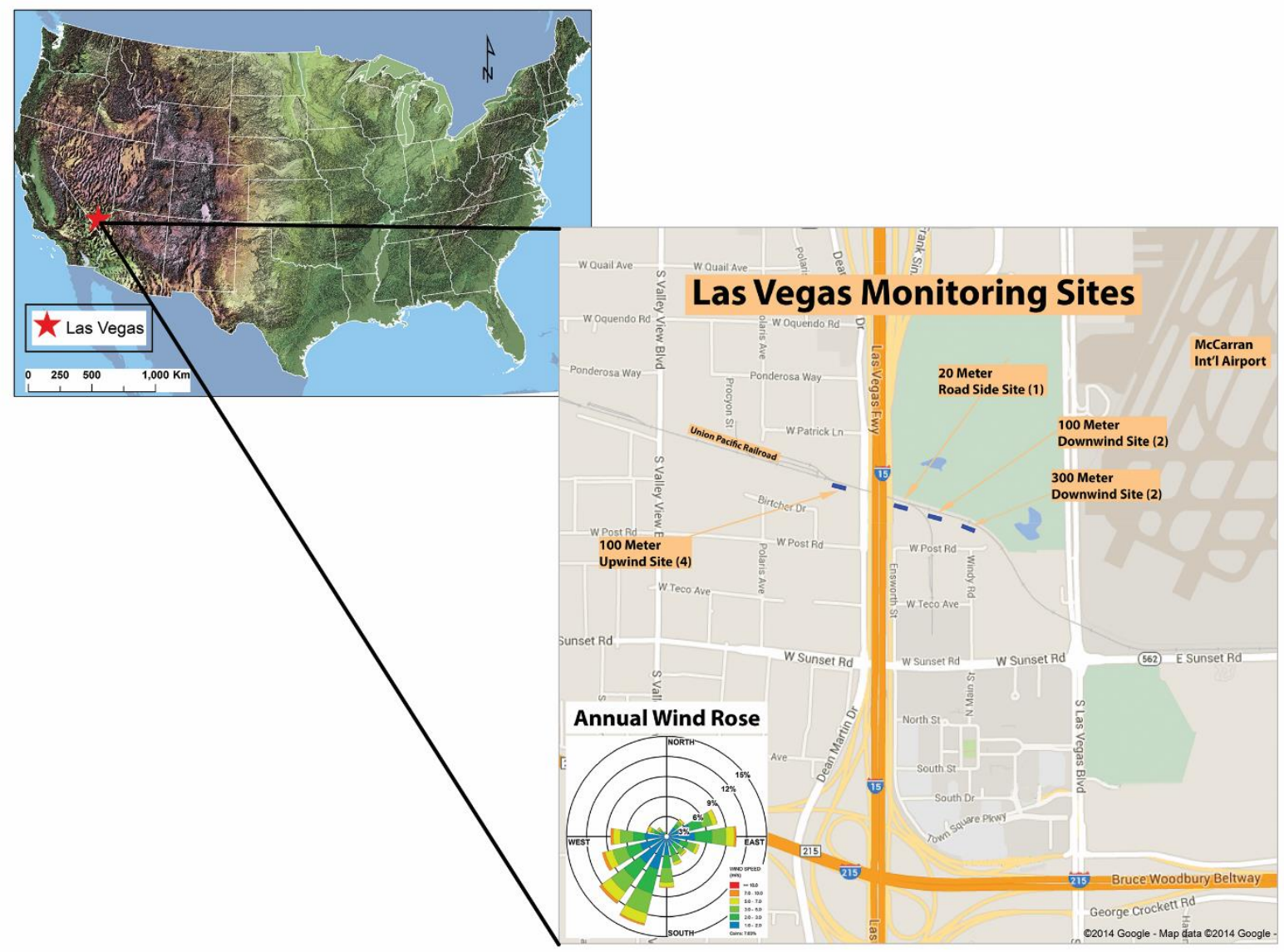

Figure S1. Map of Las Vegas monitoring sites.

Near-Road Measurements. The Las Vegas near-road study followed a monitoring protocol, which outlined a uniform approach to evaluate the dispersion patterns and contributions 
of mobile sources to air toxic compounds. ${ }^{4}$ Measurements included $\mathrm{CO}, \mathrm{CO}_{2}, \mathrm{NO}, \mathrm{NO}_{2}, \mathrm{NO}_{\mathrm{X}}$, $\mathrm{SO}_{2}, \mathrm{BC}, \mathrm{PM}_{\text {Coarse }}, \mathrm{PM}_{10}, \mathrm{PM}_{2.5}, 1-3$, butadiene, benzene, acrolein, acetaldehyde, formaldehyde, wind speed, wind direction, temperature, humidity, solar radiation, and precipitation. ${ }^{5}$ Particle counts were also measured in six size bins $(20-30,30-50,50-70,70-100,100-200$, and $>200 \mathrm{~nm})$ using an ultrafine particle monitor (Model 3031, TSI, Inc). After passing through an inlet conditioned to a stable relative humidity using an in-line nafion dryer, the UFP 3031 instrument size-segregates particles by using a differential mobility analyzer, followed by counting via an electrometer. In this manner, the six size bins are sampled sequentially (approximately 1.5 minutes per size bin) and the counts are reported at 15-minute time intervals. In addition, the instrument used to measure black carbon, an Aethaometer manufactured by Magee Scientific, also indicated UVPM, which has been shown to be indicative of brown carbon in biomass smoke. ${ }^{6}$ Measurements taken at the near-road project site and discussed herein include BC, UVPM, $\mathrm{CO}, \mathrm{PM}_{10}$, and ultrafine particle counts.

Additional PM Filter Samples. Clark County Department of Air Quality (DAQ), the air quality agency responsible for administering the air pollution control program for the Las Vegas urban area, provided thirty-two $47 \mathrm{~mm}$ Teflon samples and 7 blanks, which were deployed at the following Clark County DAQ identified Las Vegas locations: JD Smith (northeast Las Vegas, neighborhood site), Jean (south-southwest of Las Vegas, background site), Apex (north-northeast of Las Vegas, background site), and Joe Neal (northwest Las Vegas, neighborhood site).

Clark County DAQ adhered to their quality assurance project plan (QAPP) which uses Federal Reference Method (FRM) samplers in accordance with Title 40, part 50 of the CFR Appendix L (40 CFR Part 50) when they collected samples from the identified locations. Clark County DAQ then provided the collected filter samples to EPA in mid-2010. Clark County DAQ submits an 
annual certification to EPA that officially states that all data collected during the previous calendar year has been submitted to EPA and is usable for EPA regulatory uses (http://www.clarkcountynv.gov/depts/AirQuality/Pages/Monitoring_Reports.aspx).

Levoglucosan (Lg) Sample Preparation and Analysis. In late 2010, EPA analyzed the samples and used reduced-volume solvent extraction and gas chromatography-mass spectrometry (GC-MS) methods similar to those described earlier to determine Lg concentrations in the PM. ${ }^{7} \quad$ EPA measured $\mathrm{Lg}$ concentrations to determine the presence and strength of biomass fire aerosol at the four Clark County DAQ ambient air monitoring sites over a 22-day sampling period from August 14 to September 4, 2009. Lg was detected at all four of the Clark County DAQ ambient air monitoring sites on each day. Overall, the Lg values reported here are well within the range of ambient concentrations collected globally $(0.007-8 \mu \mathrm{g} \mathrm{m}-3)$ within the 2000-2010 decade. Sizeable input from residential wood combustion was not expected due to the late summer timeframe under investigation.

HSPLIT. Clark County DAQ also ran HYSPLIT for multiple time periods during these episodic events. The Clark County DAQ data shows the transport of air pollutants from southern California to the Las Vegas, NV urban area. ${ }^{8,9}$ As shown in Supplemental Information, Figure S4 and S5, satellite images from the Geostationary Operational Environmental Satellite (GOES11) and Moderate Resolution Imaging Spectroradiometer (MODIS) during the period of August 28 thru September 3, 2009 indicates smoke from the Station fire being transported into southern Nevada. ${ }^{9}$ Figure S6 shows Aeronet aerosol optical depth (AOD) for the month of August 2009 for Frenchman Flat, the closest Aeronet measurement site to Las Vegas. This figure shows that during the last few days of August, 30 and 31, the reduced visibility from the transport of air pollutants from southern California to the Las Vegas, NV area. ${ }^{10}$ 


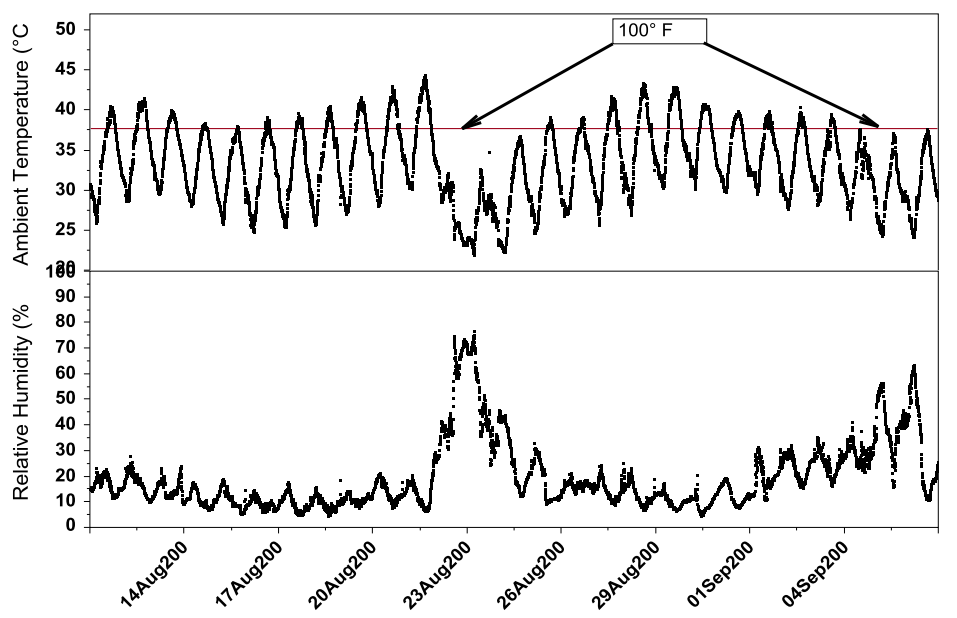

Figure S2. Ambient temperature and relative humidity, August 14, 2009 thru September 4, 2009.

\section{Example of Smokey Conditions in Las Vegas area During California Wildfires.}

Smoke from wildfires can impact visibility and are characterized by "smoky" conditions. ${ }^{11-21}$ An example of these smoky conditions is shown in Figure S3, a picture of the Las Vegas skyline on August 31, 2009.

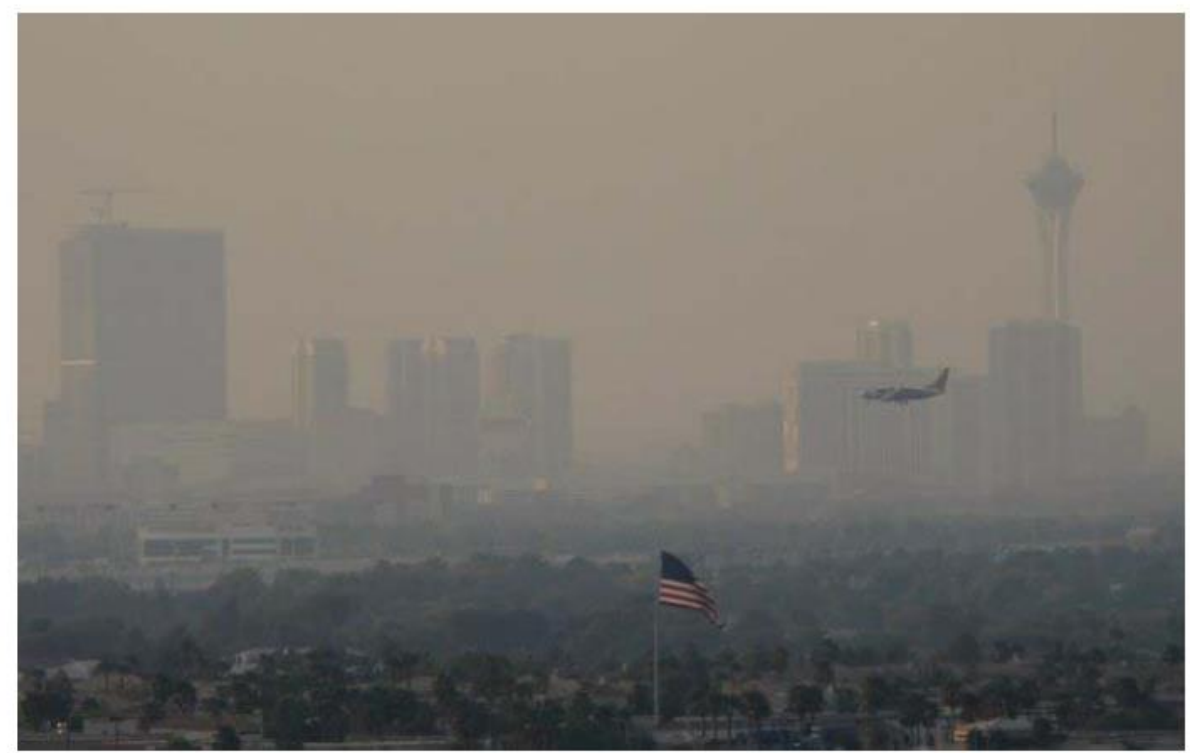

Steve Marcus

Smoke from California wildfires obscures the Las Vegas skyline in this photo taken from Henderson Monday, Aug. 31, 2009.

Figure S3. Las Vegas skyline during California wildfires. ${ }^{22}$ 
Levoglucosan Sample Preparation and Analysis. Levoglucosan ( $\mathrm{Lg}$ ) concentrations in the PM were determined using reduced-volume solvent extraction and gas chromatographymass spectrometry (GC-MS) methods similar to those described earlier (Hays et al. ${ }^{7}$ and refs. therein). Briefly, $25 \mathrm{~mm}$ to $37 \mathrm{~mm}$ diameter Teflon filter punches containing PM sample were transferred to amber vials ( $7 \mathrm{~mL})$, spiked with $10 \mu \mathrm{L}$ of a 13C-Lg internal standard solution (100 $\mathrm{ng} / \mu \mathrm{L})$, and extracted in methanol $(2 \mathrm{~mL})$ aided by mild sonication $(\sim 40 \mathrm{~min})$. Extracts were concentrated to $300 \mu \mathrm{L}$. In order that $\mathrm{Lg}$ was more amenable to GC-MS analysis, a $10 \mu \mathrm{L}$ extract aliquot was derivatized with $50 \mu \mathrm{L}$ of (N,O-bis(trimethylsilyl) trifluoroacetamide) and trimethylchlorosilane reagent, which replaced active hydrogens with a trimethyl silyl group adding thermal stability. The mixture was heated $(30 \mathrm{~min})$ at $70{ }^{\circ} \mathrm{C}$, and analyzed immediately by GC-MS to avoid hydrolysis.

Silyated extract $(1 \mu \mathrm{L})$ was introduced to the GC-MS (Models 6890 and 5973, Agilent Technologies) using an auto-injector with the inlet functioning in split mode (10:1). The GC column (DB-5, Agilent Technologies, $60 \mathrm{~m}$ x $.25 \mathrm{~mm}$ i.d. x $0.25 \mu \mathrm{m}$ film thickness) temperature was held constant for $10 \mathrm{~min}$ at $65^{\circ} \mathrm{C}$ and ramped $\left(10{ }^{\circ} \mathrm{C} / \mathrm{min}\right)$ to $300{ }^{\circ} \mathrm{C}$ where it was held constant for $30 \mathrm{~min}$. The helium carrier gas flow was $1 \mathrm{~mL} / \mathrm{min}$. Electronic pneumatic control (EPC) kept the target compound retention times fixed during the analysis period. The MS was operated in single ion monitoring (SIM) mode (13C-Lg target ion $338 \mathrm{~m} / \mathrm{z}$, qualifiers-206 m/z and $220 \mathrm{~m} / \mathrm{z} ; \mathrm{Lg}$ target ion $204 \mathrm{~m} / \mathrm{z}$, qualifiers- $147 \mathrm{~m} / \mathrm{z}, 217 \mathrm{~m} / \mathrm{z}, 333 \mathrm{~m} / \mathrm{z}$ ). A method detection limit (MDL) of $0.21 \mathrm{ng} / \mu \mathrm{L}$ for $\mathrm{Lg}$ was determined in accordance with SW 846 guidelines. ${ }^{23}$ Replicate injections $(\mathrm{n}=7)$ of a $1.5 \mathrm{ng} \mathrm{Lg} / \mu \mathrm{L}$ standard solution-which was 3 times less than the practical quantification limit-resulted in an MDL of $0.2 \mathrm{ng} / \mu \mathrm{L}$. Lg concentrations were determined using the average response factor (relative standard deviation $=19.8 \%$ ) produced 
from multi-level calibration data $(5 \mathrm{ng} / \mu \mathrm{L}$ to $100 \mathrm{ng} / \mu \mathrm{L})$. Mid-level calibration checks were performed at a frequency of every 10 samples and showed an accuracy $\geq 88 \%$. All $\operatorname{Lg}$ values reported as part of the current study were background corrected using a field blank average $(\mathrm{n}=$ 7); $\mathrm{Lg}$ was detected in the filter blanks at $6 \%$ (or less) of the detected sample mass on average. A matrix spike recovery of $\mathrm{Lg}$ was calculated as $109.9 \%$ and a carryover of $<3 \%$ was determined via sample re-extraction. Replicate GC-MS sample injections were within $15 \%$ of one another on average.

Quality Assurance. Quality assurance project plans (QAPPs) applicable to the results discussed herein, $\mathrm{BC}$, UVPM, CO, $\mathrm{PM}_{10}$, ultrafine particle counts, and levoglucosan, include EPA approved QAPPs for: (1) measurements taken at the near-road project site (BC, UVPM, $\mathrm{CO}, \mathrm{PM}_{10}$, and ultrafine particle counts); (2) levoglucosan laboratory analysis. In addition, filters used for the levoglucosan laboratory analysis were supplied by Clark County DAQ, the local air quality agency responsible for administration of the air pollution control program for the Las Vegas urban area. These samples were collected by Clark County DAQ using Federal Reference Method (FRM) samplers in accordance with Title 40, Part 50 of the Code of Federal Regulations, Appendix L (40 CFR Part 50). The filter samples were provided to EPA in mid2010 and were analyzed in late-2010. Gravimetric filter results are submitted to EPA's Air Quality System (AQS) database. Moreover, the Clark County PM $_{2.5}$ FRM sampling network is operated under the Clark County quality assurance project plan (QAPP) and is subject to a Performance Evaluation Program (PEP) audit and the results are submitted to EPA's AQS database. The Clark County DAQ data are collected and submitted to EPA's AQS database. ${ }^{8}$ 
Satellite Images during California Wildfire Events. Satellite imagery showing evidence of the large fire in Angeles National Forest (Station Fire) and confirmation of visibility deterioration and wildfire plumes transported from California in late-August, 2009 (Figure S4 and S5).

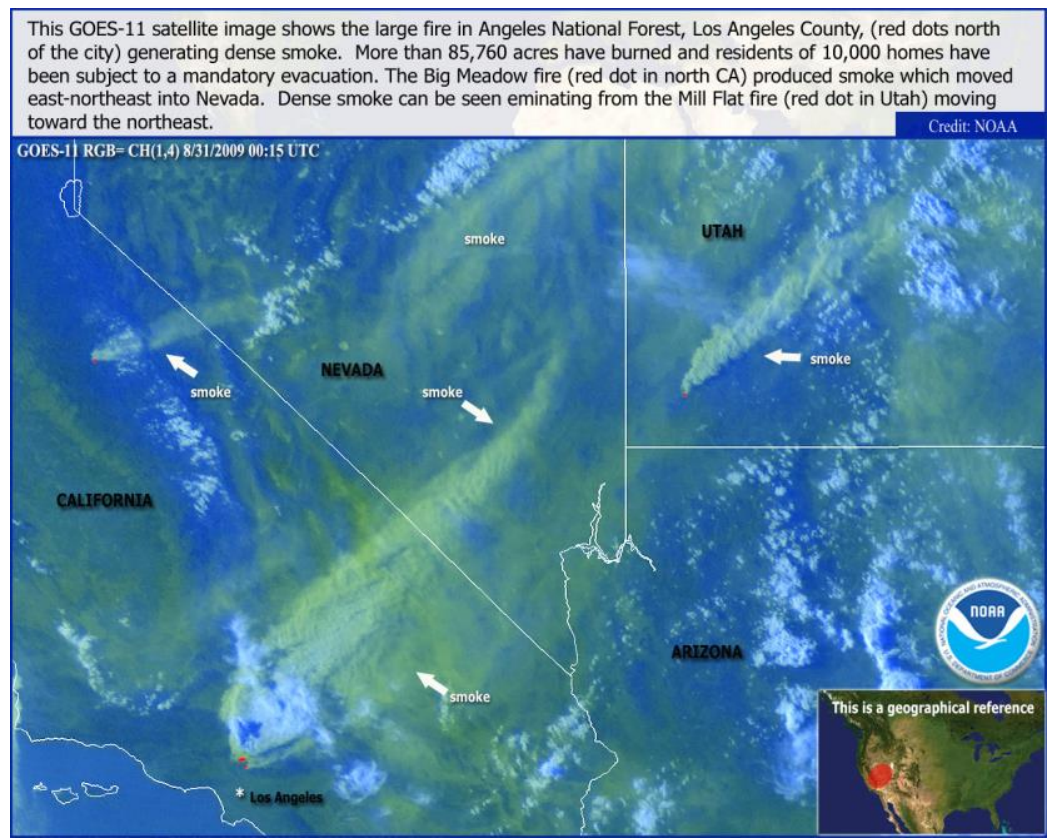

Figure S4. Image of Smoke from California Fires Reaching Nearly Across Nevada.' 


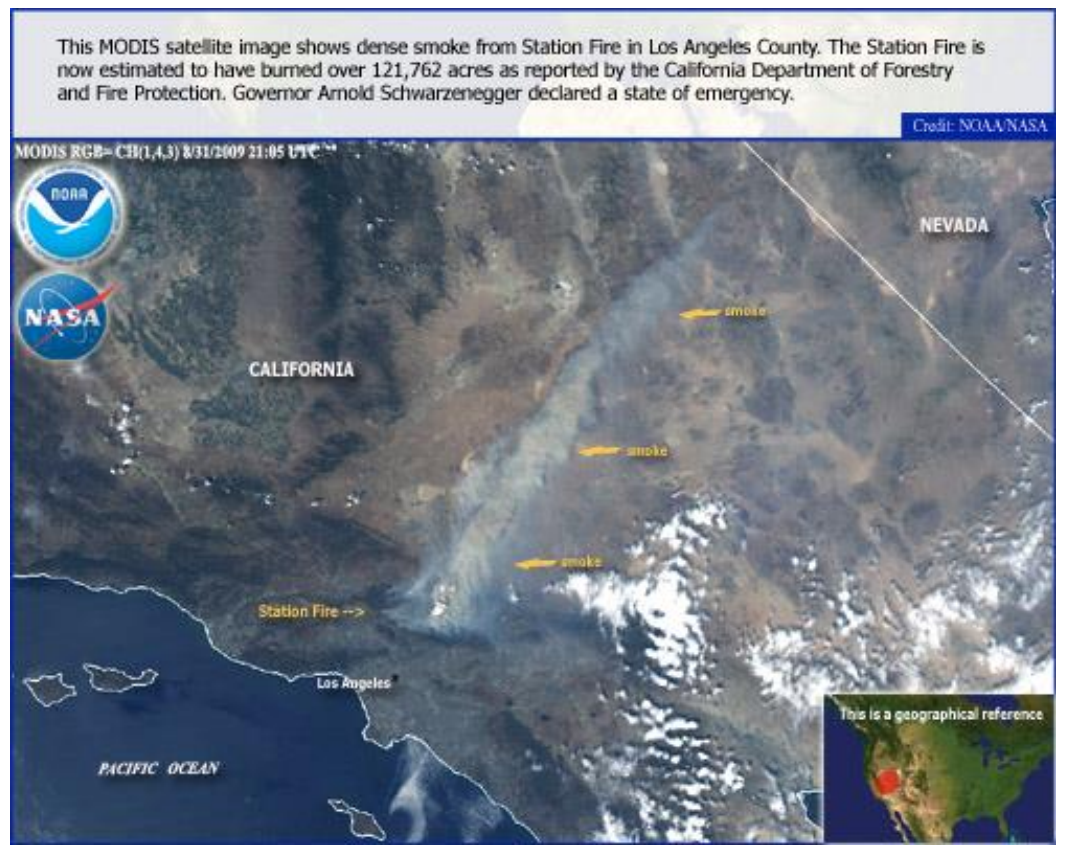

Figure S5. MODIS Satellite Image of Smoke from California Fires Reaching Nevada. ${ }^{9}$

As shown in Figure S6, Aeronet Aerosol Optical Data for Frenchman Flat for August 2009, the aerosol optical thickness displays a significant increase for the last few days of August 2009 which corresponds to the time period of smoke transport from the California wildfires into Nevada and the Las Vegas area. 


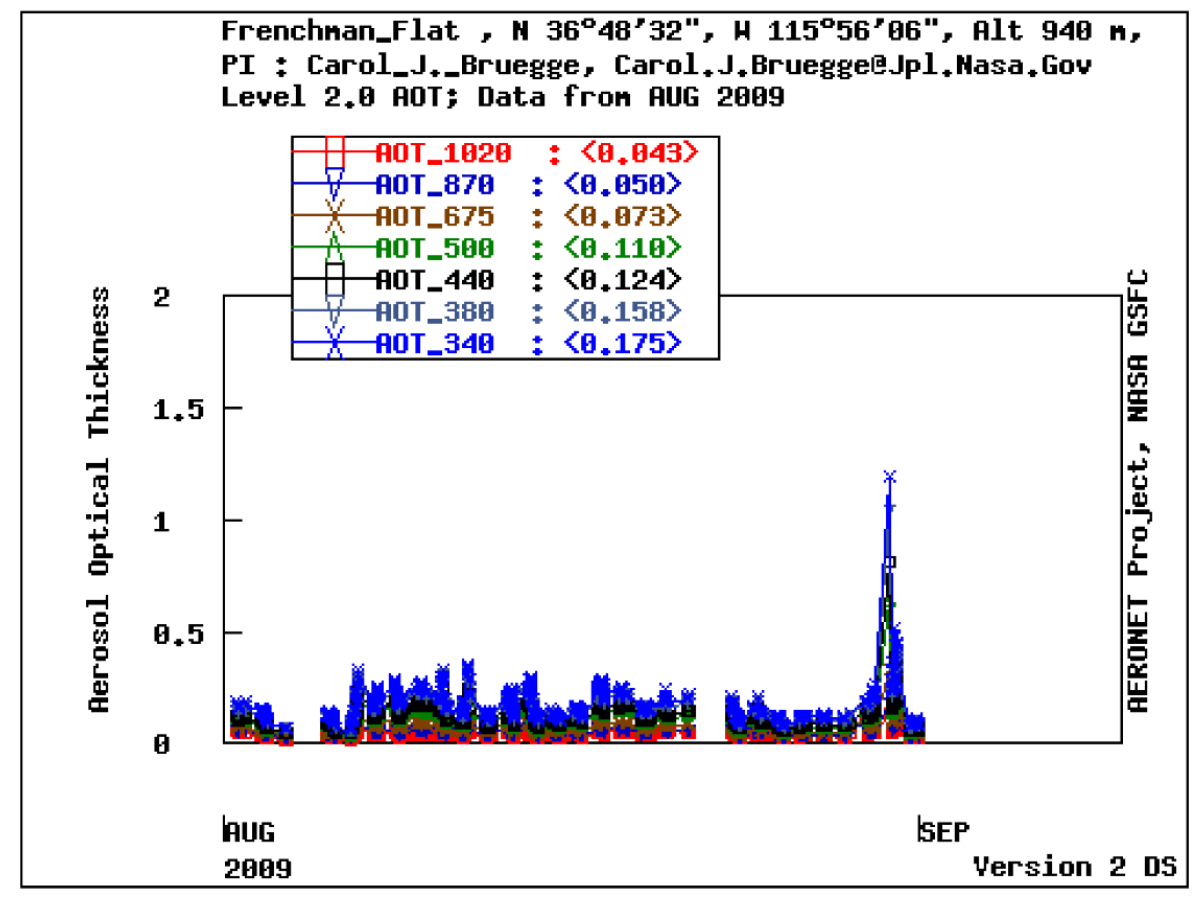

Figure S6. Aeronet Aerosol Optical Data for Frenchman Flat for August 2009. ${ }^{10}$ 
To isolate the influence of biomass burning smoke compared to other factors that may influence roadside pollution, further constraints applied to the data were requiring wind from the road (210-330 degrees), wind speed within 2-4 $\mathrm{m} \mathrm{s}^{-1}$, traffic volume between 500-2000 (counts per 15 min increment). In addition, the days of the week used for comparison were isolated to Saturday, Sunday, and Monday, corresponding to the biomass burning event time span detected in Las Vegas. Sampling hours were confirmed to be similar between the two time periods - the selection for moderate wind speeds and wind from the road resulted in the majority of the observations occurring during evening and early morning hours (Figure S7).

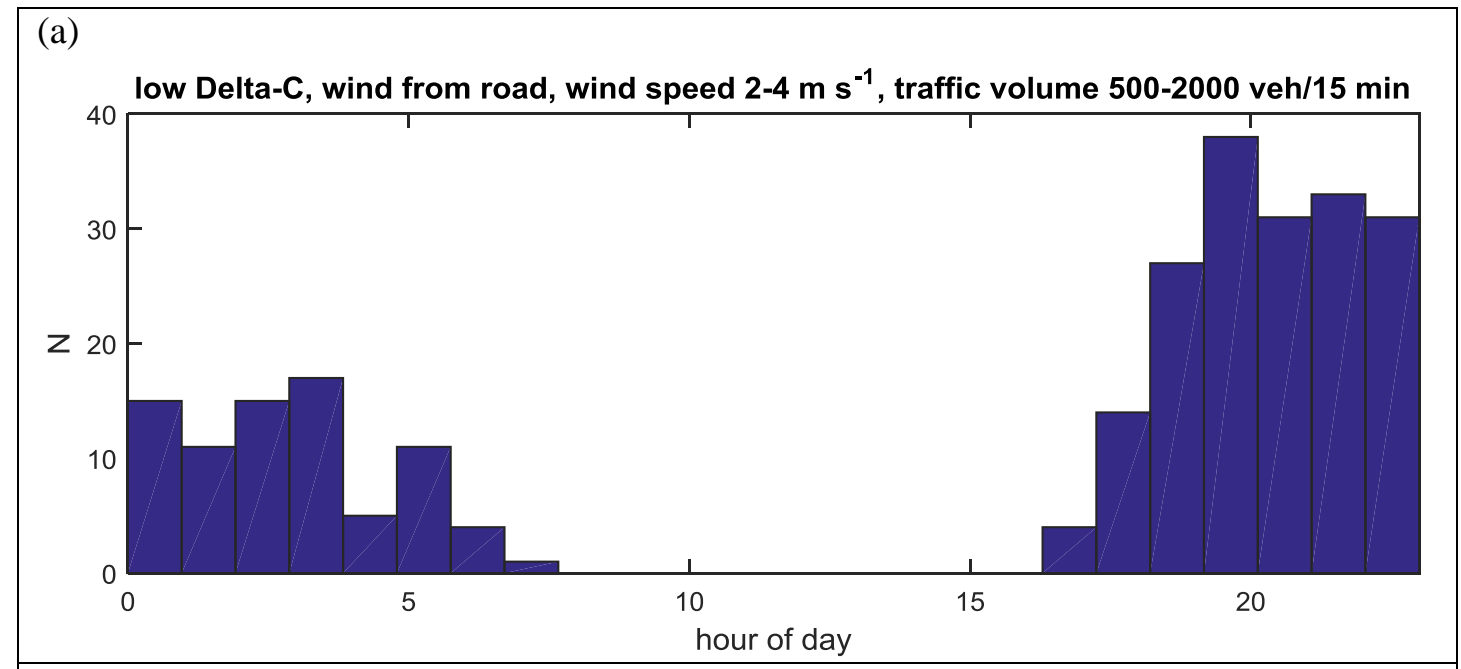

(b)

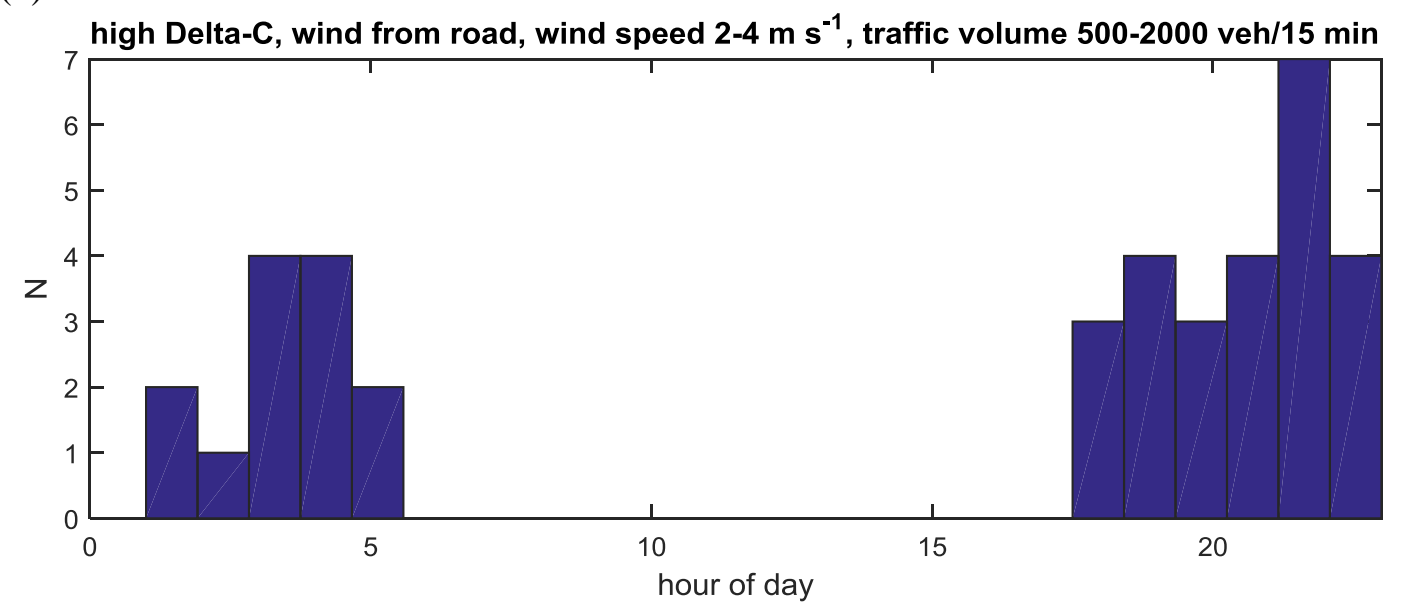

Figure S7. Hourly distribution of Delta-C: (a) Low Delta-C, wind from road, wind speed 2-4 m/s, traffic volume 500-2000 veh/15min, (b) High Delta-C, wind from road, wind speed 2-4 m/s, traffic volume 500$2000 \mathrm{veh} / 15 \mathrm{~min}$. 


\section{REFERENCES}

(1) InciWeb La Brea Fire. http://www.inciweb.org/incident/1803/ (last accessed: November 25, 2012).

(2) InciWeb Station Fire. http://www.inciweb.org/incident/1856/ (last accessed: November 25, 2012).

(3) Clark County DAQEM Clark County Air Quality Events. http://ccaqapps5m.co.clark.nv.us/cgibin/events.pl (last accessed: September 21, 2012).

(4) FHWA, Detailed monitoring protocol for U.S. 95 settlement agreement.

(5) Kimbrough, S.; Baldauf, R.; Hagler, G.; Shores, R. C.; Mitchell, W.; Whitaker, D. A.; Croghan, C. W.; Vallero, D. A., Long-term continuous measurement of near-road air pollution in Las Vegas: Seasonal variability in traffic emissions impact on local air quality. Air Quality, Atmosphere \& Health 2013, 6, (1), 295-305.

(6) Wang, Y.; Huang, J.; Zananski, T. J.; Hopke, P. K.; Holsen, T. M., Impacts of the Canadian Forest Fires on Atmospheric Mercury and Carbonaceous Particles in Northern New York. Environmental Science \& Technology 2010, 44, (22), 8435-8440.

(7) Hays, M. D.; Gullett, B.; King, C.; Robinson, J.; Preston, W.; Touati, A., Characterization of Carbonaceous Aerosols Emitted from Outdoor Wood Boilers. Energy Fuels 2011, 25, (12), 5632-5638.

(8) Clark County DAQEM Clark County Air Quality Data. http://ccaqapps5m.co.clark.nv.us/cgibin/select_summary.pl (last accessed: September 21, 2012).

(9) Clark County DAQEM Clark County Air Quality Events. http://airquality.clarkcountynv.gov/cgibin/DAQ/events.pl (last accessed: July 18, 2013).

(10) NASA Aeronet AOD. https://catalog.data.gov/dataset/aeronet-aod (last accessed: September 10, 2015).

(11) Langmann, B.; Duncan, B.; Textor, C.; Trentmann, J.; van der Werf, G. R., Vegetation fire emissions and their impact on air pollution and climate. Atmospheric Environment 2009, 43, (1), 107-116.

(12) Phuleria, H. C.; Fine, P. M.; Zhu, Y.; Sioutas, C., Air quality impacts of the October 2003 Southern California wildfires. J. Geophys. Res. 2005, 110.

(13) Sapkota, A.; Symons, J. M.; Kleissl, J.; Wang, L.; Parlange, M. B.; Ondov, J.; Breysse, P. N.; Diette, G. B.; Eggleston, P. A.; Buckley, T. J., Impact of the 2002 Canadian forest fires on particulate matter air quality in Baltimore City. Environmental Science \& Technology 2005, 39, (1), 24-32.

(14) Sillanpaa, M.; Saarikoski, S.; Hillamo, R.; Pennanen, A.; Makkonen, U.; Spolnik, Z.; Van Grieken, R.; Koskentalo, T. A.; Salonen, R. O., Chemical composition, mass size distribution and source analysis of long-range transported wildfire smokes in Helsinki. Science of the Total Environment 2005, 350, (1-3), 119-135. 
(15) Viswanathan, S.; Eria, L.; Diunugala, N.; Johnson, J.; McClean, C., An analysis of effects of San Diego wildfire on ambient air quality. Journal of the Air \& Waste Management Association 2006, 56, (1), 56-67.

(16) Wiedinmyer, C.; Quayle, B.; Geron, C.; Belote, A.; McKenzie, D.; Zhang, X. Y.; O'Neill, S.; Wynne, K. K., Estimating emissions from fires in North America for air quality modeling. Atmospheric Environment 2006, 40, (19), 3419-3432.

(17) Bein, K. J.; Zhao, Y. J.; Johnston, M. V.; Wexler, A. S., Interactions between boreal wildfire and urban emissions. Journal of Geophysical Research-Atmospheres 2008, 113, (D7).

(18) Colarco, P. R.; Schoeberl, M. R.; Doddridge, B. G.; Marufu, L. T.; Torres, O.; Welton, E. J., Transport of smoke from Canadian forest fires to the surface near Washington, D. C.: Injection height, entrainment, and optical properties. Journal of Geophysical Research-Atmospheres 2004, 109, (D6).

(19) DeBell, L. J.; Talbot, R. W.; Dibb, J. E.; Munger, J. W.; Fischer, E. V.; Frolking, S. E., A major regional air pollution event in the northeastern United States caused by extensive forest fires in Quebec, Canada. Journal of Geophysical Research-Atmospheres 2004, 109, (D19).

(20) Vedal, S.; Dutton, S. J., Wildfire air pollution and daily mortality in a large urban area. Environmental Research 2006, 102, (1), 29-35.

(21) Wu, J.; Winer, A. M.; Delfino, R. J., Exposure assessment of particulate matter air pollution before, during, and after the 2003 Southern California wildfires. Atmospheric Environment 2006, 40, (18), 3333-3348.

(22) Toplikar, D., Smokey skies to continue across Las Vegas tonight. Las Vegas Sun August 31, 2009, 2009.

(23) U.S., E., Test Methods for Evaluating Solid Waste, Physical/Chemical Methods. 